\section{De aasspade, een strandschopje voor volwassenen?}

\section{Johan David}

Museum voor de Oudere Technieken

$\mathrm{Nu}$ en dan zie je bij eb nog oude(re) mannen putjes graven in het natte zand op het strand. Ze bouwen geen zandkastelen, maar zoeken naar zeepieren, 15 tot $20 \mathrm{~cm}$ lange bruinrode of groenbruine wormen. Die diertjes worden veel gebruikt als aas in de (sport)zeevisserij; de oude wetenschappelijke naam was trouwens Arenicola piscatorum, d.i. zeepier van de vissers. De beroepsvissers vingen hun wormen zelf, vele sportvissers kochten ze in de winkel of van "beroepsjagers": zo'n 25 jaar geleden zouden er jaarlijks honderdduizenden van verkocht zijn. (') Voor een aantal gepensioneerden betekende dat een niet te verwaarlozen bijverdienste.

De zeepier (Arenicola marina) leeft voornamelijk in het zand van slijkerige stranden - dat van Heist was vroeger beroemd om het aantal vondsten... Op die stranden tref je soms grote aantallen hoopjes zand aan met $15 \mathrm{~cm}$ verder een trechtervormig putje. Gaatje en hoopje zijn de twee uiteinden van een verticale $\mathrm{U}$-vormige buis, woonplaats van de zeepier. Via de trechter zuigt de worm zand aan, dat water en sedimenten bevat. Na vertering van de voedingstoffen, wordt het zand weggeworpen en vormt het rolronde hoopjes aan het andere uiteinde van de buis. $\left({ }^{2}\right)$

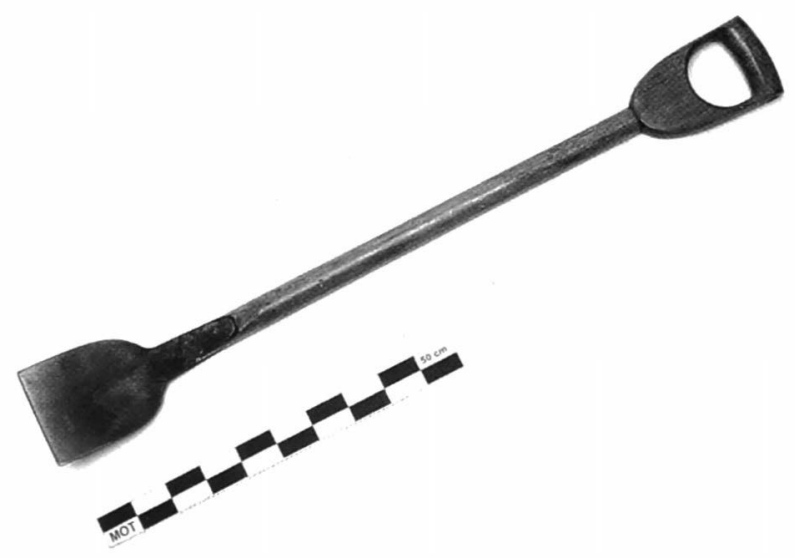

Om een zeepier te vangen moet je dus telkens een putje graven, soms tot $50 \mathrm{~cm}$ diep. Belangrijk daarbij is de graafsnelheid. Bij onraad graaft het diertje zich immers snel in het zand. Eenmaal gevangen, wordt de pier in een houten recipiënt met water gegooid, in metaal sterft hij immers. ( $\left.{ }^{3}\right)$ Wanneer ze niet onmiddellijk gebruikt worden, worden de diertjes in de zon gelegd of aan een draad geregen, en
Afb. 1: industrieel gemaakte aasspade

MOT V $89.0232 \mathrm{~L}=102 \mathrm{~cm}$

$B=13 \mathrm{~cm} \mathrm{G}=1,550 \mathrm{~kg}$. Opschrift: Polet Borsbeke

(1) J. SCHREINER, Encyclopedie van de sportvisserij, AmsterdamBrussel, 1973/4: s.v. zeepier.

(2) G. LAMOTTE, Wandelen langs de Noordzee van Het Zoute tot De Panne. Natuurgids van de Belgische kust. Biotopen, flora en fauna, Antwerpen, 1998: p.157.

(3) Le véritable guide du pêcheur par l'oncle Pierre, Parijs, s.d.: p.327; Guide du pêcheur belge. Rivières. canaux, étangs et lacs de chez nous, s.l., 1949: p. 129. 
Afb. 2: aasspade gemaakt van een afgedankte infanterieschop MOT V $89.0233 \mathrm{~L}=98 \mathrm{~cm}$ $B=12 \mathrm{~cm} \mathrm{G}=1,4 \mathrm{~kg}$

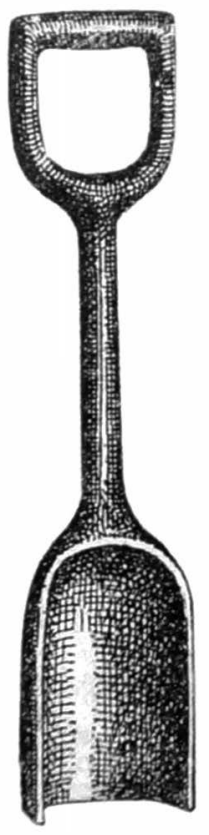

Afb. 3: uit Nouveau Larousse illustré

(4) Guide. 129.

(5) B.v. F.J. WEIJS, Sporen van een ambacht.Visserij, s.l., 1993: pp. 176177.

(6) De Nouveau Larousse illustré, Parijs, s.d., s.v. palot, spreekt van ijzer of hout maar beeldt nog een houten werktuig af.

(7) Informatie van G. Smissaert (Oostende) en J. Hoppeline (Oostduinkerke).

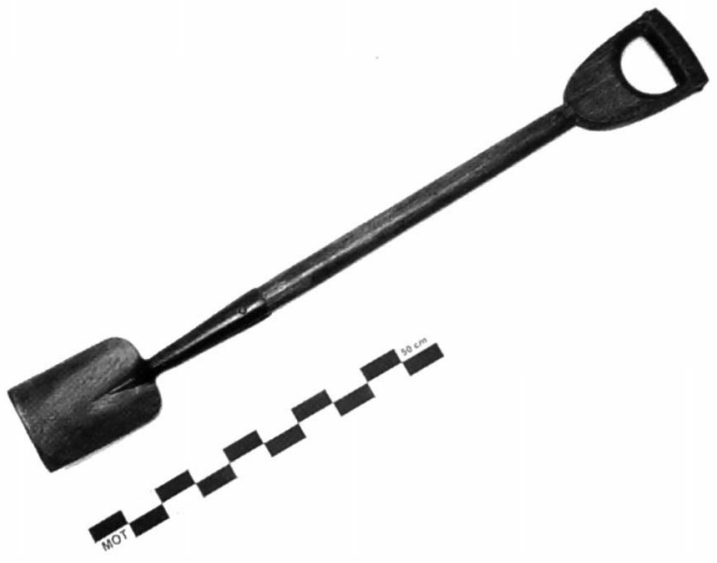

gedroogd. Een paar uren voor gebruik worden ze in een vochtige vod gewikkeld. $\left({ }^{4}\right)$ Ze kunnen ook een paar dagen in het zout bewaard worden.

Bij het graven gebruikt men soms een vork, $\left({ }^{5}\right)$ maar veelal een spade. Geen gewone spit- of steekspade, maar wel een aasspade. Lang geleden was ze van hout, al dan niet beslagen (afb. 1). $\left(^{6}\right.$ ) Al meer dan honderd jaar $\left({ }^{7}\right)$ werd ze aan de Vlaamse kust evenwel van ijzer gemaakt (sommigen hebben spaden van aluminium geprobeerd, maar het zand glijdt er te snel van af). Kenmerkend voor de aasspade is een klein blad (ca $15 \times 12 \mathrm{~cm}$ ), om snel te kunnen graven, dat in een kleine hoek staat met de steel, om diep te kunnen graven. Zoals de spit- en steekspaden aan de kust heeft ook deze een D-steel. Het werktuig is ongeveer één meter lang en weegt zo'n 1,5 kg.

Dergelijke aasspaden werden machinaal gemaakt o.m. door Madear (Ardooie) en Polet (Herzele) (afb. 2), maar vroeger ging de voorkeur naar spaden gemaakt door de smid, vb. Breurs in De Panne. Wanneer er geen smid meer was die dergelijke spaden nieuw kon vervaardigen, liet men er een smeden uit achtergelaten werktuigen van het leger; één van de exemplaren van het MOT werd gemaakt van een infanterieschop van het Canadese leger (afb. 3).

De aasspade verslijt snel. Geen wonder als men denkt aan de schurende werking van het zand en als men weet dat, naar het schijnt, zo'n 120.000 putjes per jaar gegraven werden. $\left({ }^{7}\right) \mathrm{Na}$ een jaar is het werktuig al versleten. Men recupereert dan de steel én de dille (of de veren) en men laat er een nieuw blad op lassen.

Vandaag is de aasspade aan het verdwijnen. Ze blijkt niet meer gefabriceerd te worden, en slechts uitzonderlijk kan men nog een nieuw exemplaar kopen. Haar ouderdom is nog niet bekend, ook nict van 


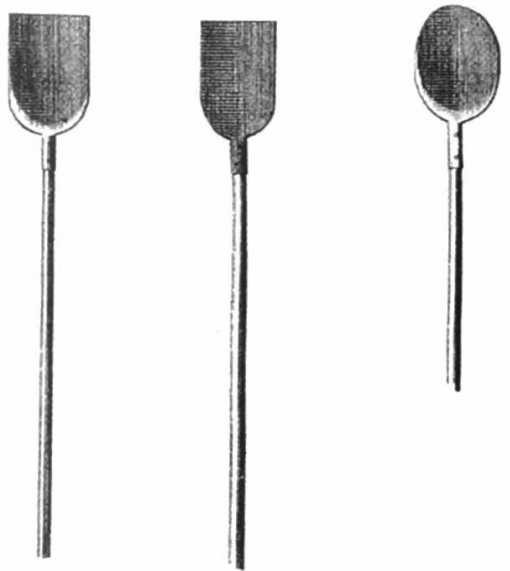

het model dat we aan onze kust gebruikten. Het oudste spoor tot dusver vindt men in de beschrijving van Duhamel du Monceau, die er zou kunnen op wijzen dat er reeds in de 18 de eeuw speciale spaden gemaakt werden om "wormen" te vangen (afb. 4). ${ }^{8}$ )

In welke andere landen ze nog gebruikt werd, is evenmin bekend. Men moet trouwens rekening houden met het feit dat men de zeepier blijkbaar ook al wadend in het water of vanuit een bootje ving. In Denemarken en Duitsland ging men daarvoor eerst met een plonsstok te werk. Men harkte de diertjes samen en haalde ze uit het water met een $70 \mathrm{~cm}$ lange houten tang. $\left({ }^{9}\right)$

Wat die jacht ten slotte betekende voor onze kustbevolking dient eveneens nog onderzocht te worden. Totnogtoe hebben historici en volkskundigen geen aandacht geschonken aan de "jacht" op de zeepier of aan de aasspade. Er kunnen nu nog getuigen ondervraagd worden. Wie voelt zich geroepen?
Afb. 4: uit Duhamel

du Monceau

(8) H.L. DUHAMEL DU MONCEAU, Les arts de la pêche. I.Traité général des pêches... in Description des arts et métiers, Parijs, 1769: 3e section, pl. 1: "ce sont des pelles, palots, bêches, louchets, les uns de bois; les autres de fer, d'autres de bois dont les bords sont garnis de fer, pour aller chercher dans le sable plusieurs sortes de poissons \& de vers. On leur donne différentes formes suivant l'usage des différents pays".

(9) M. VON DEM BORNE DE BERNEUCHEN, Le carnet $d u$ pêcheur, Verviers, 1893: p.277. 